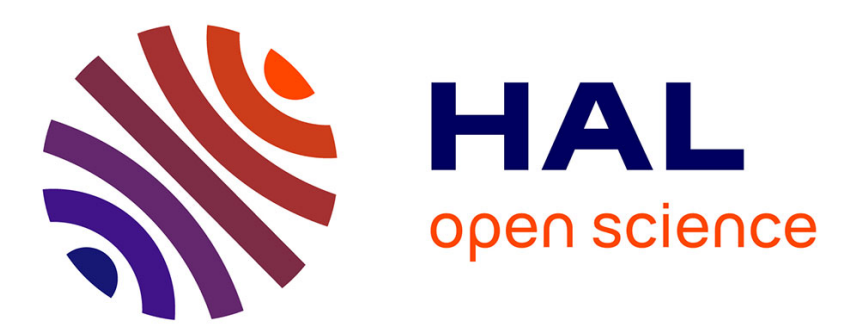

\title{
Atypical Stoichiometry for a 3D Bimetallic Oxalate- Based Long-range Ordered Magnet Exhibiting High Proton Conductivity
}

Catalin Maxim, Sylvie Ferlay, Hiroko Tokoro, Shin-Ichi Ohkoshi, Cyrille Train

\section{- To cite this version:}

Catalin Maxim, Sylvie Ferlay, Hiroko Tokoro, Shin-Ichi Ohkoshi, Cyrille Train. Atypical Stoichiometry for a 3D Bimetallic Oxalate- Based Long-range Ordered Magnet Exhibiting High Proton Conductivity. Chemical Communications, 2014, 50 (42), pp.5629-5632. 10.1039/c4cc00607k . hal-01596217

\author{
HAL Id: hal-01596217 \\ https://hal.science/hal-01596217
}

Submitted on 27 Sep 2017

HAL is a multi-disciplinary open access archive for the deposit and dissemination of scientific research documents, whether they are published or not. The documents may come from teaching and research institutions in France or abroad, or from public or private research centers.
L'archive ouverte pluridisciplinaire HAL, est destinée au dépôt et à la diffusion de documents scientifiques de niveau recherche, publiés ou non, émanant des établissements d'enseignement et de recherche français ou étrangers, des laboratoires publics ou privés. 


\title{
Atypical Stoichiometry for a 3D Bimetallic Oxalate- Based Long-range Ordered Magnet Exhibiting High Proton Conductivity
}

\author{
Catalin Maxim, ${ }^{\mathrm{a}, \mathrm{b}, \mathrm{c}}$ Sylvie Ferlay ${ }^{\mathrm{a}, \mathrm{c}, *}$, Hiroko Tokoro, ${ }^{\mathrm{e}}$ Shin-Ichi Ohkoshi ${ }^{\mathrm{e}}$ and \\ Cyrille Train ${ }^{\mathrm{b},} \mathrm{d}, \mathrm{f}, *$
}

The reproducible formation of a 3D oxalate based coordination compound with an unusual $\mathrm{Mn}^{\mathrm{II}} / \mathrm{Cr}^{\mathrm{III}}$ stoichiometry, of formula $\left(\mathrm{NH}_{4}\right)_{5}\left[\mathrm{Mn}_{2} \mathrm{Cr}_{3}(\mathrm{ox})_{9}\right] .10 \mathrm{H}_{2} \mathrm{O}$, is presented. The unprecedented topology of the anionic network leads to antiferromagnetic long-range ordering whereas its guests favour high humidity-dependent proton conductivity.

\section{Introduction}

New materials with targeted physical properties are of current interest. Molecular materials, with their inherent chemical flexibility, represent good candidates to reach this goal. Metal-organic frameworks $(\mathrm{MOF})^{1}$ are indeed structurally diverse platforms that allow not only the introduction of a single property such as gas storage, sensors, magnetism or catalysis ${ }^{2}$ but also of several properties leading to multifunctional materials. Since their discovery, ${ }^{3}$ oxalate-based extended networks of general formula $\left[\mathrm{M}_{\mathrm{a}}^{\mathrm{II} / \mathrm{III}} \mathrm{M}_{\mathrm{b}}^{\mathrm{I} / \mathrm{II}}\left(\mathrm{C}_{2} \mathrm{O}_{4}\right)\right]_{\mathrm{n}}^{2 \mathrm{n}-/ \mathrm{n}-}$ have focused lot of attention in that direction because the anionic network provide magnetic properties and is able to host a wide variety of functional cations, paving the way to a rational synthesis of magnetic multifunctional materials. ${ }^{4}$ In particular, electron conduction was introduced in such networks through tetrathiafulvalene (TTF) derivatives cationic stacks inserted between the anionic layers. ${ }^{5}$ This approach has culminated with the synthesis of a molecular ferromagnetic conductor.6 A revival of the influence of the electric field recently appears in oxalate-based systems following two distinct objectives: the introduction of ferroelectricity towards molecular multiferroics ${ }^{7}$ and the development of proton conductivity within the material. ${ }^{8}$ It should be noted that MOFs exhibiting the latter phenomenon have received little attention despite its importance for promoting efficient fuel cells. ${ }^{9,10}$

The introduction of proton conductivity in oxalate-based compounds was first studied by Kitagawa et al.8 Their strategy relies on the introduction of acidic or hydrophilic residues into the cationic component in order to construct proton-conductive pathways between the anionic bimetallic layers. Recently, Pardo et al. ${ }^{11}$ described an oxalate-based network of formula $\left(\mathrm{NH}_{4}\right)_{4}\left[\mathrm{MnCr}_{2}(\mathrm{ox})_{6}\right] \cdot 4 \mathrm{H}_{2} \mathrm{O}$ (2) whose proton conduction is related to the presence of ammonium and/or crystallization water molecules within one-dimensional channels. Interestingly, this compound exhibits a three-dimensional (3D) quartz-like coordination network that strongly contrasts with the well-known 2D $(6,3)$ and $3 \mathrm{D}(10,3)\left[\mathrm{M}_{\mathrm{a}}^{\mathrm{II} / \mathrm{III}} \mathrm{M}_{\mathrm{b}}{ }^{\mathrm{I} / \mathrm{II}}\left(\mathrm{C}_{2} \mathrm{O}_{4}\right)\right]_{\mathrm{n}}{ }^{2 \mathrm{n}-}$ networks generally encountered in oxalate-based coordination networks. ${ }^{12}$ This example raised two sets of important questions about (i) the metal stoichiometry and the topology of such networks (ii) the mechanisms of the proton conduction in such high dimensional architectures.

In this communication, we report the formation of a $3 \mathrm{D}$ bimetallic oxalate-bridged compound of formula $\left(\mathrm{NH}_{4}\right)_{5}\left[\mathrm{Mn}_{2} \mathrm{Cr}_{3}(\mathrm{ox})_{9}\right] \cdot 10 \mathrm{H}_{2} \mathrm{O}$ (1). This unconventional $2 / 3$ $\mathrm{Mn}^{\mathrm{II}} / \mathrm{Cr}^{\mathrm{III}}$ stoichiometry leads is to an unprecedented structure that is carefully described together with the analysis of the magnetic properties and the humidity-dependent conduction properties.

\section{Results and discussion}

Crystals of 1 were obtained under self-assembly conditions 13 by using a $\mathrm{MeOH}$ solution containing ammonium tris(oxalato)chromate(III) and manganese(II) chloride followed by a slow diffusion of a $1 / 1 \mathrm{CH}_{3} \mathrm{OH} / \mathrm{CHCl}_{3}$ mixture (see ESI). Whereas the salts are essentially the same than those previously used to obtain bimetallic oxalate-based networks, ${ }^{11}$ it appears that the original solvent mixture used herein addresses reproducibly the unprecedented $2 / 3 \mathrm{Mn}^{\mathrm{II}} / \mathrm{Cr}^{\mathrm{III}}$ stoichiometry observed in 1. Originally introduced as a counterion favouring the dissolution of trisoxalatometalate(III) salts in non aqueous solvents, the ammonium cations now appear as template cations of this very unusual bimetallic oxalate-bridged coordination networks. The observed metal ion ratio indeed corresponds to an original structural arrangement, detailed thereafter, that takes advantage of the robustness of the tris(oxalato)chromate(III) building block and of the versatility of the coordination modes of both the manganese(II) and the oxalate ions.

The crystal structure of 1 was solved by single-crystal X-ray diffraction (table $\mathrm{S} 1$ in ESI). 1 crystallizes in the achiral $\mathrm{C} 2 / \mathrm{c}$ space group with the formula $\left(\mathrm{NH}_{4}\right)_{5}\left[\mathrm{Mn}_{2} \mathrm{Cr}_{3}(\mathrm{ox})_{9}\right] \cdot 10 \mathrm{H}_{2} \mathrm{O}$. The compound is composed of a $3 \mathrm{D}$ anionic coordination network 
with cavities filled by ammonium cations and water molecules. Whereas one of the five ammonium cations needed to balance the charge of the anionic network was solved in the compound, the squeeze command was used for the structural refinement and, on the basis of TGA measurements and elemental analysis, four other ammonium cations and ten water molecules were found to be also present in the network (Fig. S4 in ESI).
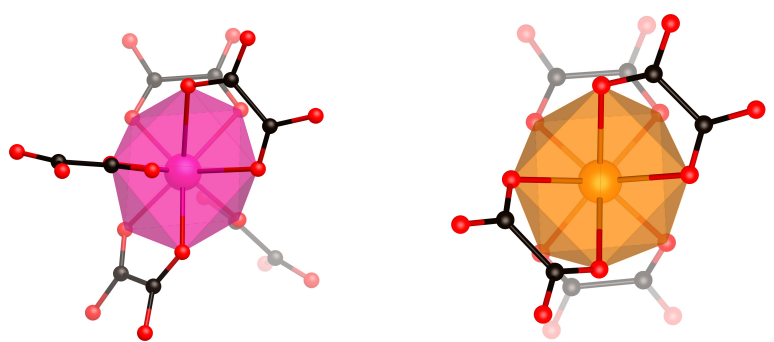

Figure 1: Representation of the $\mathrm{Mn}$ coordination environments in 1 for $\mathrm{Mn} 1$ (left) and Mn2 (right).

Within the network, both independent chromium atoms are surrounded by three oxalate ligands forming a slightly distorted octahedral environment, with $\mathrm{Cr}-\mathrm{O}$ distances in the 1.963(6) and 2.004(8) $\AA$ range. $\mathrm{Cr} 1$ is coordinated, via oxalate bridges to three $\mathrm{Mn}$ atoms in a triangular pyramidal environment, with MnCrMn angles of $102.46,108.41$ and $123.52^{\circ}$, whereas $\mathrm{Cr} 2$ behaves as a planar triangular bridge between three $\mathrm{Mn}$ atoms in the xOy plane.
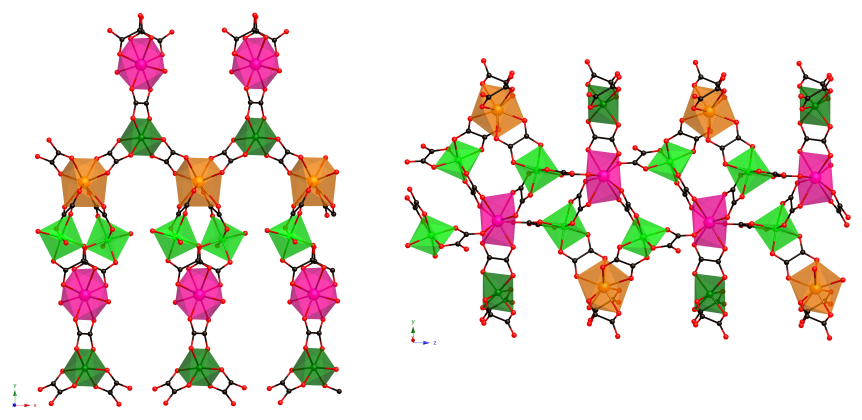

Figure 2: Representation of the bimetallic anionic network in 1 (fuschia $=\mathrm{Mn} 1$ gold $=\mathrm{Mn} 2$, light green $=\mathrm{Cr} 1$, dark green $=\mathrm{Cr} 2$ ) along the $a$-axis (left) and along the $c$-axis (right).

There are two types of manganese(II) in the unit cell. Both are coordinated to eight oxygen atoms located at the vertices of a distorted lozenge antiprism (Fig. 1 and $\mathrm{S} 1$ ). Mn1 is coordinated to two oxygen atoms from different oxalate ligands that act as bidentate-monodentate ligands and to three oxalate ligands in a bisbidentate coordination mode (Fig. 1 left and $\mathrm{S} 1$ left). The shortest $\mathrm{Mn}-\mathrm{O}$ distance $(2.265(5) \AA)$ corresponds to the monodentate coordination mode. The oxalate ions bridging the two faces of the prism exhibit a short (2.272(4) $\AA$ ) and a long (2.491(5) $\AA$ ) Mn-O distances whereas the two oxygen atoms of the bidentate oxalate located on one face of the prism are at 2.342(4) $\AA$ of the Mn1 atom. Owing to the mixed coordination modes of the oxalate ligands, $\mathrm{Mn} 1$ has coordination links with 5 chromium(III) ions with $\mathrm{Mn}-\mathrm{Cr}$ distances in the 5.330(6)-
5.634(6) $\AA$ range (Fig. 2 and $\mathrm{S} 1$ left). The situation is simpler for Mn2: it is surrounded by four oxalate ligands in a bisbidentate coordination mode (Fig. 1 right and S1 right). Each oxalate occupies an edge of a lozenge and has one short (2.249(5) or 2.267(5) $\AA$ ) and one long (2.424(6) and 2.367(5) $\AA$ respectively) $\mathrm{Mn}-\mathrm{O}$ distances. It is thus coordinated to four chromium(III) ions being located at distances of $\mathrm{Mn} 2$ ranging between 5.574(6) and 5.596(6) $\AA$ (Fig. 2 right). To get an overall topological view of the material, one can figure out that both $[\mathrm{Cr}(\mathrm{ox}) 3] 3$ - moieties are connected to $3 \mathrm{Mn}$ (II) ions, whereas the $\mathrm{Mn}(\mathrm{II})$ ions act as five and four $\mathrm{Cr}$ (III) ions connectors (Fig. 2, left). The anionic 3D coordination network can be represented (Fig. S2 top) and described14 in terms of network topology as $\left\{3.6^{4} .8\right\}\left\{3^{4} \cdot 4^{2} \cdot 5^{4}\right\}\left\{3^{3} \cdot 6^{4} \cdot 7^{2} \cdot 8\right\}\left\{3^{5} \cdot 4^{2} \cdot 5^{3} \cdot 6^{4} \cdot 7\right\}$ point symbols for the four metallic ions representing the network (Mn2, Mn1, Cr2 and $\mathrm{Cr} 1$ respectively). This network is totally unprecedented since it is not enumerated in RCSR and Topos.14 The variety of the coordination modes of the oxalate ligand together with the versatility of the octacoordinated manganese(II) ions acting as either four- or five-connectors, allow the formation of this original network.

The anionic network is crossed by two types of channels running along the a-axis (Fig. S2 top). The first one is delimited by a distorted lozenge formed by two $\mathrm{Cr} 1$ and two Mn1 metal ions. The lozenges are sharing edges along the c-axis. The channel section is ca. $3.1 \times 4.2 \AA 2$. In these channels, one ammonium ion was refined (Fig. S2 bottom). It establishes $\mathrm{H}-$ bonds with a terminal oxygen atom of a non-bridging oxalate (O17) with $\mathrm{dN}-\mathrm{O}$ distances of $2.940(5) \AA$ and with an oxygen atom of a bridging oxalate $(\mathrm{dN}-\mathrm{O}=2.985(6) \AA)$. It is thus in a distorted tetrahedral environment with $\mathrm{ONO}$ angles in the range of 55.97 and $144.34^{\circ}$. The second type of channel is delimited by highly flatten octagons. The vertices of each octagon are four $\mathrm{Cr} 1$, two $\mathrm{Mn} 1$ and two Mn2 metal ions. The channel section is ca. $5.4 \times 11.5 \AA 2$. Additional electronic density from water molecules and ammonium ions are located in both types of channels, which could not be safely assigned to water molecules or ammonium cations.

The comparison with the $3 \mathrm{D}$ parent compounds of formula $\left(\mathrm{NH}_{4}\right)_{4}\left[\mathrm{MnCr}_{2}(\mathrm{ox})_{6}\right] \cdot 4 \mathrm{H}_{2} \mathrm{O} \quad(2),{ }^{11}$ and also with $\left[\mathrm{Ru}(\mathrm{bpy})_{2}(\right.$ ppy $\left.)\right]\left[\mathrm{MnCr}(\mathrm{ox})_{3}\right](\mathbf{3})^{4 \mathrm{c}}$ is important to understand the formation of this coordination network presenting an original connectivity. In all three compounds $\mathbf{1 - 3}$, the tris(oxalate)chromate(III) tecton is fully preserved. Nevertheless its connections with manganese(II) ions are slightly different. Whereas in $\mathbf{2}$, tris(oxalato)chromate(III) acts as a bis(bidentate) metalloligand, in $\mathbf{3}$, it acts a tris(bidentate) metalloligand. In $\mathbf{1}$, an intermediary situation is reached: as in 3, $\mathrm{Cr} 2$ behaves as a tris(bidentate) metalloligand but $\mathrm{Cr} 1$ is a monodentate-bis(bidendate) metalloligand. This situation is rather scarce. It has been encountered in $\operatorname{rad}\left[\mathrm{Mn}\left(\mathrm{H}_{2} \mathrm{O}\right) \mathrm{Cr}(\mathrm{ox})_{3}\right] \cdot 2 \mathrm{H}_{2} \mathrm{O} \quad\left(\mathrm{rad}^{+}=2-, \quad 2-(1-\right.$ methylpyridinium4-yl)-4,4,5,5-tetramethylimid-azoline-1-oxyl-3-oxide) ${ }^{15}$,

$\left[\mathrm{Co}(\text { tpy })_{2}\right]\left[\mathrm{Mn}\left(\mathrm{H}_{2} \mathrm{O}\right) \mathrm{Cr}(\mathrm{ox})_{3}\right] \cdot 5 \mathrm{H}_{2} \mathrm{O} \cdot \mathrm{CH}_{3} \mathrm{OH} \quad\left(\right.$ tpy $=2,2^{\prime}: 6^{\prime}, 2^{\prime \prime}-$ terpyridine) $)^{16}$ 
$\left[\mathrm{Mn}\left(\mathrm{OH}_{2}\right)_{2}\left(\mathrm{CH}_{3} \mathrm{OH}\right)_{2}\right]\left[\mathrm{Mn}\left(\mathrm{CH}_{3} \mathrm{OH}\right)\left(\mathrm{OH}_{2}\right)\right]_{2}\left[\mathrm{Cr}(\mathrm{ox})_{3}\right]_{2}(18 \mathrm{C} 6)$ $\left(18 \mathrm{C} 6=\mathrm{C}_{12} \mathrm{H}_{24} \mathrm{O}_{6}\right) \cdot{ }^{17}$ Moreover, 1 differs from other compounds by the environment of the manganese(II) ions. In $\mathbf{1}$, $\mathrm{Mn} 2$ is surrounded by four bidentate oxalate ligands. This coordination mode appears to be much the same as the one observed in 2. Nevertheless, the polyhedron evolves from a square antiprism in $\mathbf{1}$ to a bicapped triangular prism in $\mathbf{2}$ and, accordingly, the $\mathrm{Mn}-\mathrm{O}$ distances span over a wider range in the latter compound. As stated in ref. 11, this situation is scarcely encountered in the literature. Finally, the environment of Mn1 (three bidentate oxalate ligands and two monodentate ones) is the most surprising. In CCDC, it is only found once for a $\mathrm{Ba}$ (II) ion in the discrete cluster of formula $\mathrm{Ba}_{4}\left[\mathrm{Fe}_{6}{ }_{6}\left(\mu_{3^{-}}\right.\right.$ $\left.\mathrm{OH})_{6}\left(\mathrm{C}_{2} \mathrm{O}_{4}\right)_{6}\right] \mathrm{Br}_{2} \cdot 6 \mathrm{H}_{2} \mathrm{O}^{18}$ but it was never observed for any transition metal ion coordinated by oxalate ions or in any oxalate-based extended coordination network. This unusual coordination environment of $\mathrm{Mn} 1$ deeply modifies the connecting rules within the network and leads to the construction of this highly original coordination network.

The magnetic measurements were performed on microcrystalline powder of 1 checked by PXRD (Fig. S3, ESI) The thermal variation of cMT for 1 , where $\mathrm{cM}$ is the molar magnetic susceptibility per $\mathrm{Mn} 2 \mathrm{Cr} 3$ unit and $\mathrm{T}$ the absolute temperature, is shown in Fig. 3. The cMT value of 14.80 $\mathrm{cm} 3 \mathrm{~mol}-1 \mathrm{~K}$ at room temperature is slightly higher than the value calculated for uncoupled magnetic ions $(\mathrm{SMn}=5 / 2, \mathrm{SCr}$ $=3 / 2 ; \mathrm{cMT}=14.375 \mathrm{~cm} 3 \mathrm{~mol}-1 \mathrm{~K}$ with $\mathrm{gCr}=\mathrm{gMn}=2.0)$. $\mathrm{cMT}$ increases continuously when $\mathrm{T}$ decreases, until reaching a maximum value of $35.0 \mathrm{~cm} 3 \mathrm{~mol}-1 \mathrm{~K}$ at $6.0 \mathrm{~K}$. The $\mathrm{cMT}$ then undergoes an abrupt decrease at low temperature. This behaviour is indicative of dominant $\mathrm{Mn}-\mathrm{Cr}$ ferromagnetic (F) exchange interaction through the oxalate bridge. To quantify this interaction, the thermal variation of the inverse of the susceptibility was fitted by a Curie-Weiss law between 20 and $300 \mathrm{~K}$ leading to a value of the Curie-Weiss temperature $\mathrm{Q}=$ 4.0 K (Fig. 3 top). Moreover, the field-cooled magnetization (FCM) exhibits a peak at $\mathrm{TN}=6.0 \mathrm{~K}$ which is indicative of the onset of an antiferromagnetic (AF) order with a Néel temperature of $6.0 \mathrm{~K}$ (Fig. 3, bottom).

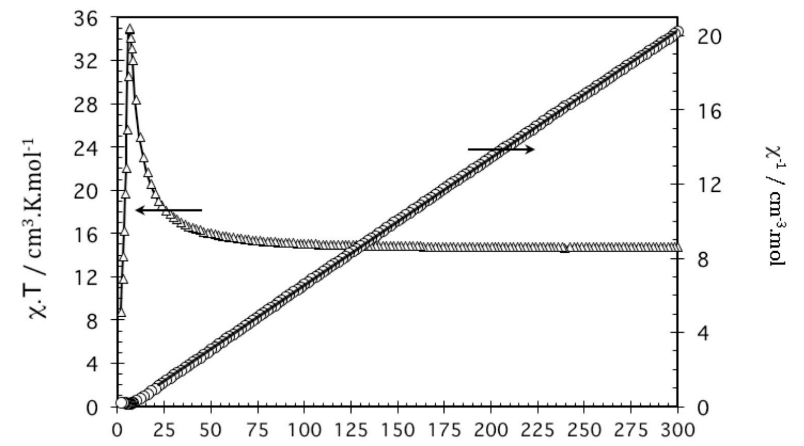

$\mathrm{T} / \mathrm{K}$

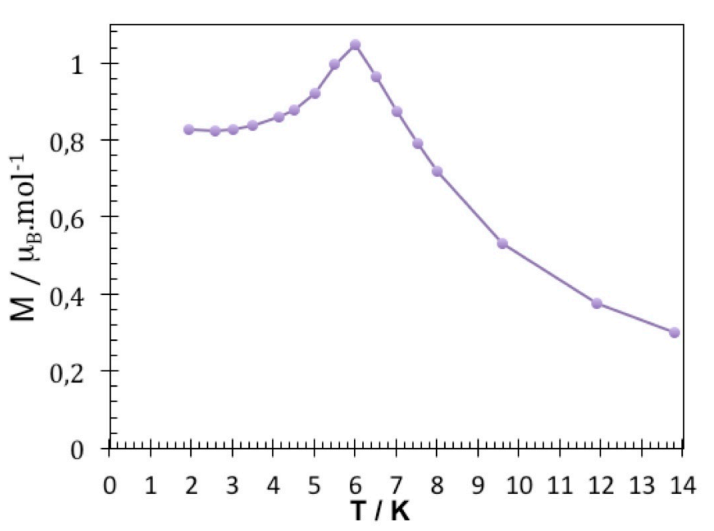

Figure 3: Thermal dependence of $c_{M} T$ and $c_{M}{ }^{-1}$ (top) and field-cooled magnetization (FCM) for $\mathbf{1}$ (bottom).

There seems to be a contradiction between the nature of the exchange interaction deduced from the treatment of the susceptibility and the nature of the long-range magnetic order (LRMO) deduced from the FCM. The comparison between the Curie-Weiss and the Néel temperatures is the first element to solve this ambiguity. The Curie-Weiss temperature can be related to the exchange interaction parameters using a meanfield approach known as molecular field. ${ }^{19}$ This has two consequences: (i) when only one interaction is present, because of quantum fluctuations not taken into account in the meanfield approach, the absolute value of the Curie-Weiss temperature is always greater than the LRMO temperature (ii) when several exchange interaction are present, the Curie-Weiss temperature averages the different exchange interaction parameters. In the case of $\mathbf{1}$, it means that a dominant $\mathrm{F}$ interaction coexists together with either a weaker $\mathrm{F}$ interaction or even an AF one. The latter situation is the only compatible with the onset of an AF LRMO. A close look at the structure brings complementary information on the nature of the exchange interaction. In the $[\mathrm{MnCr}]$ oxalate-bridged networks, the $\mathrm{Mn}-\mathrm{Cr}$ exchange interacrion is $\mathrm{F}$ when the oxalate bridge is symmetric. On the contrary, it becomes AF when the bridge is fairly unsymmetrical with respect to the manganese(II) ion as found in $\left[\mathrm{Mn}\left(\mathrm{CH}_{3} \mathrm{OH}\right)_{6}\right]\left[\mathrm{Mn}\left(\mathrm{CH}_{3} \mathrm{OH}\right) \mathrm{Cr}(\mathrm{ox})_{3}\right]_{2} \cdot 2 \mathrm{CH}_{3} \mathrm{OH} .{ }^{20}$ Though the structure of $\mathbf{1}$ is rather complicated, the magnetostructural analysis is quite straightforward using these guidelines. In the (ab) planes (Fig. 2 left), all the oxalate 
ligands are in a rather symmetrical bis(bidentate) bridging mode. Accordingly, the exchange interaction in these planes is F. In the $(b c)$ planes (Fig. 2 right), the situation is more complicated. Along the $b$-axis, the interaction is ferromagnetic. But along the $c$-axis, the oxalate ligands bridging $\mathrm{Mn} 1$ to $\mathrm{Cr} 1$ adopt a bidente-monodentate mode which is the extreme case of the dissymmetrical bridge observed in ref. 20. Accordingly, the exchange interaction along this direction is AF. The contribution of this latter interaction to the Curie-Weiss temperature leads to a decrease of its value compared to the one found in networks with only one $F$ exchange interaction. Moreover, this interaction couples AF the F-coupled (ab) planes leading to an overall AF LRMO.

Electrical measurements were performed on sintered microcrystalline powder of $\mathbf{1}$ at $298 \mathrm{~K}$ at various humidity rates (Fig. 4 and S5 in ESI). For example, for a relative humidity (RH) set at $74 \%$ of the saturation value, a Cole-Cole circular arc fitting of the curve leads to a conductivity value $\sigma$ of $7.110^{-}$ ${ }^{4} \mathrm{~S} \mathrm{~cm}^{-1}$ (Fig. 4 top). ${ }^{21}$ Let us note that the value of $74 \% \mathrm{RH}$ is the maximum we can reach in the case of 1 because above $80 \% \mathrm{RH}$, the crystals are deliquescent, preventing measuring their conducting properties. When the relative humidity is decreased, the $\sigma$ values undergo a dramatic decrease of five orders of magnitude down to $9.110^{-9} \mathrm{~S} \mathrm{~cm}^{-1}$ at $9.5 \% \mathrm{RH}$ (Fig. 4 , bottom). This behaviour is much similar to what has been observed in other oxalate-based anionic networks hosting acidic cation. ${ }^{8,11}$ The strong dependence of the conductivity upon relative humidity confirms that proton conductivity is responsible for the high conductivity of $\mathbf{1}$ and should occur through a Grotthus mechanism. ${ }^{22}$

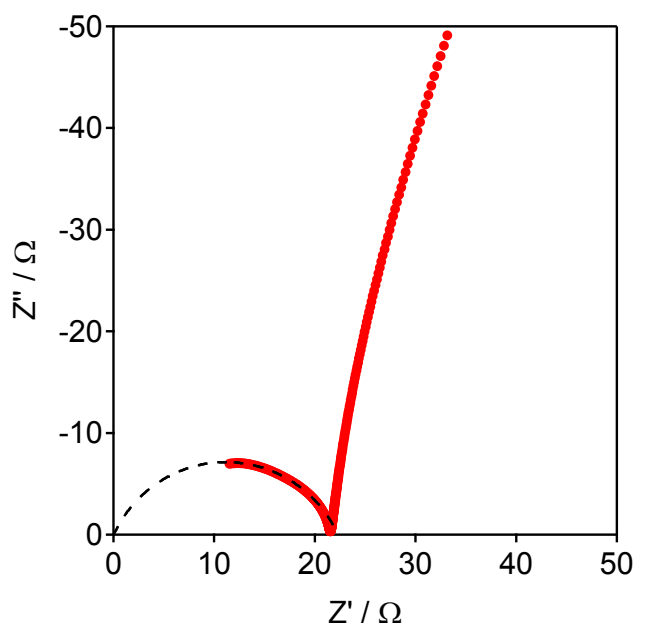

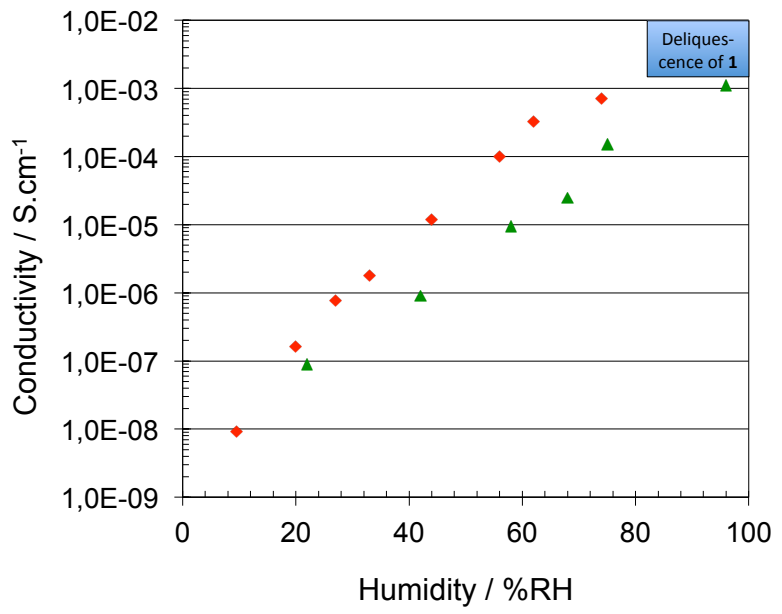

Figure 4: Cole-Cole plot for the conductivity of 1 measured in $74 \% \mathrm{RH}$ at $298 \mathrm{~K}$ (top) and dependence of the conductivity of $\mathbf{1}$ (red losange) and $\mathbf{2}$ (green triangle) at $298 \mathrm{~K}$ with the relative humidity around the sample (for $\mathbf{2}$, the data are extracted from ref. 11) (bottom).

Compared to the parent $3 \mathrm{D}$ compound $2,{ }^{11}$ the conductivity of 1 is slightly higher at comparable RH (Fig. 4 right). In the present case, a possible explanation for the increase of the protonic conductivity could be based on the enlargment of the channels section in 1 compared to the one in 2 , in particular for the octagonal ones. In turn, this enhanced accessibility to water molecules could also explained the deliquescent behaviour of compound 1 at high RH percentages. Nevertheless, in contrast with the most fruitful magnetostructural approach, the main difficulty to correlate the structure of proton conductors to their electrical behaviour, is that the identification and localisation of the molecules responsible for the conduction by X-ray diffraction are next to impossible.

\section{Experimental}

\section{Synthesis}

Except where mentioned, all the chemicals were purchased from commercial sources and were used as received. $\left(\mathrm{NH}_{4}\right)_{3}\left[\mathrm{Cr}(\mathrm{ox})_{3}\right] \cdot 3 \mathrm{H}_{2} \mathrm{O}$ was prepared following the literature procedures. ${ }^{23}$ Elemental analyses $(\mathrm{C}, \mathrm{H}, \mathrm{N})$ were carried by the Microanalytical Service of the University of Grenoble.

$\left(\mathrm{NH}_{4}\right)_{5}\left[\mathrm{Mn}_{2} \mathrm{Cr}_{3}(\mathrm{Ox})_{9}\right] \mathbf{1 0 H}_{2} \mathrm{O}$ (1).

$\left(\mathrm{NH}_{4}\right)_{3}\left[\mathrm{Cr}(\mathrm{ox})_{3}\right] \cdot 3 \mathrm{H}_{2} \mathrm{O}(85.6 \mathrm{mg}, 0.2 \mathrm{mmol})$ and $\mathrm{MnCl}_{2} \cdot 4 \mathrm{H}_{2} \mathrm{O}$ (19.8 $\mathrm{mg}, 0.2 \mathrm{mmol})$ was dissolved in $8 \mathrm{~mL}$ methanol. The resulting mixture was carefully layered to $15 \mathrm{~mL}$ solution $\mathrm{CH}_{3} \mathrm{OH} / \mathrm{CHCl}_{3} 1 / 1$. Tiny violet crystals were obtained after three days in $72 \%$ yield. Elemental analysis calculated (\%) for $\mathrm{C}_{18} \mathrm{H}_{40} \mathrm{Cr}_{3} \mathrm{Mn}_{2} \mathrm{~N}_{5} \mathrm{O}_{46}$ (1328.38): C 16.27, $\mathrm{H} \mathrm{303,} \mathrm{N}$ 5.27; found: C 16.28, H 2.85, N 5.04;

\section{Single-Crystal Studies.}

Data was collected at 173(2) K on a Bruker APEX8 CCD Diffractometer equipped with an Oxford Cryosystem liquid $\mathrm{N}_{2}$ device, using graphite-monochromated Mo-K $\alpha \quad(\lambda=$ 
$0.71073 \AA$ ) radiation. The diffraction data was corrected for absorption and structural determination was achieved using the APEX (1.022) package. The ammonium and water molecules in compound $\mathbf{1}$ are highly disordered which could not be located successfully from Fourier maps in the refinement cycles. The scattering from the highly disordered lattice guest molecules were removed using the SQUEEZE procedure implemented in the PLATON package ${ }^{24}$. The resulting new file was used to further refine the structures.

\section{Conclusions}

The synthesis of a bimetallic oxalate-bridged system, in $\mathrm{CH} 3 \mathrm{OH} / \mathrm{CHCl3}$ diffusion mixture yields a three dimensional compound of formula $\left(\mathrm{NH}_{4}\right)_{5}\left[\mathrm{Mn}_{2} \mathrm{Cr}_{3}(\mathrm{ox})_{9}\right] \cdot 10 \mathrm{H}_{2} \mathrm{O}$ presenting a remarkable $\mathrm{Mn}^{\mathrm{II}} / \mathrm{Cr}^{\mathrm{III}}$ stoichiometry. In this compound, the coordination of the manganese(II) ions are very original and, by modifying the connection rules of this ion, leads to a very intriguing $\left\{3.6^{4} .8\right\}\left\{3^{4} .4^{2} \cdot 5^{4}\right\}\left\{3^{3} \cdot 6^{4} \cdot 7^{2} .8\right\}\left\{3^{5} \cdot 4^{2} \cdot 5^{3} \cdot 6^{4} \cdot 7\right\}$ threedimensional network topology. Moreover, the architecture displays wide channels filled with water and ammonium molecules. These guests are responsible for a high proton conductivity of the compound. In addition, this proton conductor displays a long-range magnetic ordering with $\mathrm{TN}=$ $6 \mathrm{~K}$.

\section{Acknowledgements}

Pr. M. W. Hosseini is warmly acknowledged for fruitful discussions. Pr. Marc Henry is acknowledged for his help in Topos use. This work was supported by the Centre National de la Recherche Scientifique (CNRS), Université de Strasbourg (UdS), Université Joseph Fourier (UJF), Institut Universitaire de France (IUF) and the Agence Nationale de la Recherche (ANR) within the framework of the ANR-08-JCJC-0113-01 project in particular through a postdoctoral grant to C. M.

\section{Notes and references \\ ${ }^{a}$ Molecular Tectonic Laboratory, UMR UDS-CNRS 7140, Université de Strasbourg, Institut Le Bel, 4, rue Blaise Pascal, F-67000 Strasbourg, France \\ ${ }^{b}$ Laboratoire National des Champs Magnétiques Intenses, UPR CNRS 3228, 25 rue des Martyrs, B.P. 166, 38042 Grenoble cedex 9, France \\ ${ }^{c}$ University of Bucharest, Faculty of Chemistry, Inorganic Chemistry Laboratory, Str. Dumbrava Rosie nr. 23, 020464-Bucharest, Romania. \\ ${ }^{d}$ Institut Universitaire de France (IUF) \\ ${ }^{e}$ Department of Chemistry, School of Science, University of Tokyo, Tokyo 113-0033, Japan. \\ ${ }^{f}$ Université Joseph Fourier, BP 53, F-38041 Grenoble Cedex 9, France \\ E-mail : cyrille.train@lncmi.cnrs.fr, ferlay@unistra.fr}

Electronic Supplementary Information (ESI) available: X ray diffraction data, XRPD curves, TGA traces and conductivity properties.
[1] (a) S. R. Batten and R. Robson, Angew. Chem., Int. Ed., 1998, 37, 1460-1494; (b) Chem. Soc. Rev., 2009, 38, themed issue on metalorganic frameworks; (b) C. Janiak and J. K. Vieth, New J. Chem., 2010, 34, 2366-2388.

[2] Chem. Rev., 2012, 112, 2012. Metal-Organic Frameworks special issue.

[3] M. Ohba, H. Tamaki, N. Matsumoto and H. Okawa, Inorg. Chem., 1993, 32, 5385-5390.

[4] (a) S. Decurtins, H. W. Schmalle, P. Schneuwly, J. Ensling and P. Gütlich, J. Am. Chem. Soc. 1994, 116, 9521-9528; (b) M. HernándezMolina, F. Lloret, C. Ruiz-Pérez, M. Julve, Inorg. Chem. 1998, 37, 4131-4135; (c) M. Gruselle, R. Andrés, B. Malézieux, M. Brissard, C. Train, M. Verdaguer, Chirality, 2001, 13, 712-714; (d) M. Clemente-León, E. Coronado, C. J. Gómez-García and A. SorianoPortillo, Inorg. Chem., 2006, 45, 5653-5660; (e) F. Pointillart, C. Train, F. Villain, C. Cartier dit Moulin, P. Gredin, L.-M. Chamoreau, M. Gruselle, G. Aullon, S. Alvarez, M. Verdaguer, J. Am. Chem. Soc., 2007, 129, 1327-1334.

[5] M. Kurmoo, A.W. Graham, P. Day, S. J Coles, M. B. Hursthouse, J. L. Caulfield, J. Singleton, F. L. Pratt, W. Hayes, L. Ducasse, P. Guionneau, J. Am. Chem. Soc. 1995, 117, 12209-12217.

[6] E. Coronado, J. R. Galán-Mascarós, C. J. Gómez-García V. Laukhin, Nature 2000, 408, 447-449;

[7] E. Pardo, C. Train, H. Liu, L-M. Chamoreau, B. Dhkil, K. Boubekeur, F. Lloret, K. Nakatani, H. Tokoro, S-I. Ohkoshi, and M. Verdaguer Angew. Chem., Int. Ed., 2012, 51, 8356-8360

[8] (a) H. Ōkawa, A. Shigematsu, M. Sadakiyo, T. Miyagawa, K. Yoneda, M. Ohba and H. Kitagawa J. Am. Chem. Soc. 2009, 131, 13516-13522 ; (b) M. Sadakiyo, T. Yamada and H. Kitagawa J. Am. Chem. Soc. 2009, 131, 9906-9907 ; (c) M. Sadakiyo, H. Ōkawa, A. Shigematsu, M. Ohba, T. Yamada and H. Kitagawa J. Am. Chem. Soc. 2012, 134, 5472-5475 ; (d) H. Ōkawa, M. Sadakiyo, T. Yamada, M. Maesato, M. Ohba and H. Kitagawa J. Am. Chem. Soc. 2013, 135, 2256-2262 ; (e) (f) T. Yamada, K. Otsubo, R. Makiurac and H. Kitagawa Chem. Soc. Rev., 2013, 42, 6655-6669.

[9] (a) G. Ferey, F. Millange, M. Morcrette, C. Serre, M. L. Doublet, J. M. Greneche and J-M. Tarascon, Angew. Chem. Int. Ed., 2007, 46, 3259-3263 ; (b) B. M. Wiers, M. L. Foo, N. P. Balsara and J. R. Long J. Am. Chem. Soc., 2011, 133, 14522-14525.

[10] (a) S. Bureekaew, S. Horike, M. Higuchi, M. Mizuno, T. Kawamura, D. Tanaka, N. Yanai and S. Kitagawa Nat. Mater. 2009, 8, 831-836; (b) J.A. Hurd, R. Vaidhyanathan, V. Thangadurai, C.I. Ratcliffe, I.L. Moudrakovski and G.K.H. Shimizu Nat. Chem. 2009, 1, 705-710 ; (c) C. Y. Duan, M. L. Wei, D. Guo, C. He and Q. J. Meng J. Am. Chem. Soc. 2010, 132, 3321-3330 ; (d) S-I. Ohkoshi, K. Nakagawa, K. Tomono, K. Imoto, Y. Tsunobuchi and H. Tokoro J. Am. Chem. Soc. 2010, 132, 6620-6621. (e) N. C. Jeong, B. Samanta, C. Y. Lee, O. K. Farha, and J. T. Hupp J. Am. Chem. Soc., 2012, 134, 51-54; (f) S. Kim, K. W. Dawson, B. S. Gelfand, J. M. Taylor, and G. K. H. Shimizu J. Am. Chem. Soc., 2013, 135, 963-966

[11]E. Pardo, C. Train, G. Gontard, K. Boubekeur, O. Fabelo, H. Liu, B. Dkhil, F. Lloret, K. Nakagawa, H. Tokoro, S-I. Ohkoshi and M. Verdaguer J. Am. Chem. Soc., 2010, 133, 15328-15331

[12]S. Decurtins, R. Pellaux, G. Antorrena, F. Palacio Coord. Chem. Rev., 1999, 190-192, 841-854

[13]S. Mann, Nature, 1993, 365, 499-505

[14](a) Blatov, V. A. TOPOS, A Multipurpose Crystallochemical Analysis with the Program Package; Samara State University: Russia, 
2004. (b) RCSR (Reticular Chemistry Structure Resource), the associated website, http://okeeffe-ws1.la.asu.edu/RCSR/home.htm.

[15] G. Ballester, E. Coronado, C. Gimenez-Saiz, and F. M. Romero, Angew. Chem. Int. Ed. 2001, 40, 792-795

[16] Hui-Zhong Kou, O. Sato, Inorg. Chem., 2007, 46, 9513-9515

[17] E. Coronado, J.R.Galan-Mascaros, C.Marti-Gastaldo, Inorg. Chim. Acta, 2008, 361, 4017-4023

[18] B.-L. Fei, R. Clerac, C. E. Anson, A. K. Powell, Dalton Trans., 2005, 1381-1386

[19] (a) A.Herpin, Théorie du magnétisme, Bibliothèque des sciences et techniques nucléaires, 1968; (b) S.-I. Ohkoshi, K. Hashimoto, J. Am. Chem. Soc., 1999, 121, 10591-10597.

[20] E. Coronado, J. R. Galan-Mascaros, C. Marti-Gastaldo, A. M. Martınez, Dalton Trans., 2006, 3294-3299

[21] The other experiments done by varying the relative humidity (RH) are given in ESI.

[22] P. Colomban, Proton Conductors: Solids, Membranes and GelsMaterials and Devices; Cambridge University Press: Cambridge, U.K., 1992.

[23] J. C. Bailar and E. M. Jones, Inorg. Synth., 1939, 1, 37.

[24] A. L. Spek, J. Appl. Crystallogr. 2003, 36 ,7. 